\title{
Zika no Brasil: determinações de classe, gênero e raça
}

\author{
Zika in Brazil: class, gender, and racial determinants
}

Zika en Brasil: determinaciones de clase, género y raza

ZIKA NO BRASIL: HISTÓRIA RECENTE DE UMA EPIDEMIA. Löwy I. Rio de Janeiro: Editora Fiocruz; 2019. 171 p. (Coleção Temas em Saúde). ISBN: 978-85-7541-638-9.

doi: 10.1590/0102-311X00091220

Via de regra, a história das epidemias é contada linearmente: um fato definido inicia um desenvolvimento dramático, que termina com uma bem-sucedida intervenção biomédica e/ou de saúde pública. Seja pelas simplificações inerentes ao processo de escrita, seja por questões relacionadas à construção social desses eventos biológicos, por sua vez imersos em contextos históricos, políticos, econômicos e culturais 1 , fato é que as epidemias da vida real, como observa Löwi em seu livro Zika no Brasil: História Recente de uma Epidemia 2, redundam em eliminações e purificações. Com base nesse entendimento, Löwi adverte então que sua obra é "uma aproximação de uma história de um evento confuso, complexo e muito parcialmente compreendido" (p. 159), que é epidemia de Zika no Brasil entre os anos de 2015 a 2016.

Dividido em quatro capítulos, o livro traça um panorama da emergência do Zika, das epidemias da doença registradas até o momento, das principais descobertas científicas associadas à questão, das desigualdades que atravessam a crise sanitária no Brasil e, por fim, o declínio de casos e a desclassificação do quadro como uma emergência sanitária nos âmbitos nacional e global e suas repercussões.

O ponto de partida eleito por ela para contar a história da epidemia revela as lentes que guiam a sua escrita: a interseccionalidade entre saúde e questões de gênero, classe e raça. A narrativa inicia em 2008, quando o vírus Zika era considerado inócuo à saúde humana. Naquele ano, a esposa de um infectologista estadunidense que trabalhara na África contaminou-se por Zika, sugerindo a transmissão sexual do patógeno. Embora diversos estudos reforçassem a viabilidade da hipótese posteriormente e países do Norte global tenham emitido recomendações relacionadas ao sexo seguro ou até a abstinência sexual como forma de evitar o contágio de grávidas, o Ministério da Saúde foi omisso quanto ao assunto no Brasil e a Organização Mundial da Saúde (OMS) se pronunciou a respeito de forma restrita, quando emitiu orientações aos viajantes dos Jogos Olímpicos de 2016.

Aliás, Löwi não poupa críticas quanto ao negligenciamento pela OMS sobre os direitos sexuais e reprodutivos das mulheres durante a epidemia. Era contraditório, por exemplo, o órgão não se posicionar claramente quanto ao aborto nos territórios afetados, especialmente, pelas razões que motivaram o decreto da situação como uma Emergência de Saúde Pública de Importância Internacional (ESPII), sobretudo a transmissão vertical do vírus e suas consequências para os fetos. O negligenciamento desses direitos é, portanto, simultaneamente constituinte e produtor da epidemia no Brasil, que atingiu desigualmente 
mulheres pobres, negras e periféricas, segundo a autora.

Valendo-se de análises biomédicas e sociais, Löwi traz elementos para auxiliar a compreensão de como um vírus inofensivo, repentinamente, é associado a milhares de malformações congênitas no Brasil, a maioria delas no Nordeste do país. O racismo ambiental e a reprodução estratificada são causas estruturais que podem estar relacionadas à exceção do Nordeste. Por racismo ambiental entenda-se a distribuição distorcida de riscos ambientais nos diferentes segmentos da população. Já a reprodução estratificada pode ser definida pela diferença da capacidade das mulheres para controlar sua reprodução e das condições em que exercem os cuidados dos filhos por diferenças de classe/etnia/religião/cidadania. Em resumo, populações vulneráveis são mais expostas ao mosquito Aedes aegypti, transmissor da dengue, Zika e chikungunya, e também contam com menos formas de se proteger das doenças que ele transmite. Elas também têm piores de condições de vida e acesso a assistência médica e métodos contraceptivos. Ou seja, o mosquito encontra mais oportunidades de picar populações mais pobres e periféricas, que são majoritariamente não brancas, perpetuando um ciclo de pobreza e doenças, aprofundado as desigualdades existentes.

Revisitando a história da epidemia, Löwi destaca que, embora a associação entre o vírus e as malformações fetais tenha acontecido no Brasil, há evidências de uma epidemia de microcefalia durante a epidemia de Zika na Polinésia Francesa (Oceania), em 2013. Após a crise brasileira, médicos polinésios revisaram seus dados epidemiológicos e verificaram que muitas mulheres interromperam voluntariamente suas gestações legalmente, ao tomarem ciência de graves anomalias fetais.

A autora também avalia criticamente os aspectos relacionados ao desenvolvimento científico no Brasil durante a epidemia. Löwi pondera que, se por um lado, aumentou o prestígio da ciência brasileira na comunidade internacional, por outro, ficou evidente a arrogância dos pesquisadores ocidentais representada pela desconfiança nas pesquisas brasileiras, sobretudo em domínios de saber altamente especializados. $\mathrm{O}$ fato de os cientistas americanos do Centro de
Controle e Prevenção de Doenças (CDC) só terem acreditado na descoberta brasileira do vírus no líquido amniótico e nos fetos até que eles próprios obtivessem estes resultados é tido como uma atitude neocolonialista, por exemplo. Outro ponto levantado é o desequilíbrio em algumas parcerias científicas internacionais, em que os pesquisadores brasileiros eram tratados como fornecedores de amostras biológicas e dados clínicos. Além disso, Löwi ressalta a concentração na pesquisa básica e o negligenciamento das necessidades concretas das mulheres como uma característica da produção acadêmica ocidental no período.

Quanto a esse último aspecto, a autora mostra que se as questões ligadas às mulheres foram invisibilizadas ainda no momento em que o Zika era uma prioridade global, representada pela situação de ESPII, ao ser retirado o status de emergência nos planos nacional e mundial o desamparo a elas foi aprofundado. O entendimento do quadro no Brasil como uma ESPII representava, teoricamente, um esforço de recursos financeiros e intelectuais voltados não só ao esclarecimento da questão sobre a capacidade do Zika causar defeitos congênitos, como também, por exemplo, implementar medidas eficientes contra o mosquito e ações de proteção às mulheres.

Löwi aponta que, no plano nacional, o fim da emergência do Zika também significou uma redefinição de prioridades na distribuição de verbas para pesquisas, ajuda a família carentes e intervenções de saúde pública. O quadro, somado ao declínio do número de casos de bebês afetados, à crise econômica e à guinada conservadora no cenário político, relegou o Zika a um patamar de normalidade, como apenas mais uma das doenças transmitidas pelo A. aegypti, invisibilizando a situação das mulheres, sobretudo as mães de bebês afetados pelo vírus.

Estudos sociais sobre mães do Zika, segundo a pesquisadora, revelaram um quadro de negligência e lacunas no acesso aos direitos sociais e de saúde. Os relatos incluem "falta de compaixão do profissional médico diante de sua situação; grandes dificuldades no cotidiano; solidão, já que muitas delas foram abandonadas por seus companheiros; dificuldade de obter ajuda a qual tem direito, e discriminação contra crianças portadoras de malformações” (p. 133). 
Löwi finaliza sua obra ressaltando que se a possibilidade de novas epidemias de Zika é real, nem o Brasil nem o mundo tem se preparado para novos surtos da doença. Os elementos que favorecem a proliferação do A. aegypti continuam presentes: a intensificação dos movimentos populacionais, a rapidez e o volume de viagens aéreas, a urbanização caótica, as expansões de zonas da pobreza urbana e as mudanças climáticas. Ante tudo isso, é possível que o Zika, como o dengue, "estabeleça-se como uma doença com erupções periódicas de gravidade variável, e que o nascimento de crianças com sindrome do Zika se torne o novo normal em muitas partes do mundo" (p. 152).

O livro integra a coleção Temas em Saúde, editada pela Editora Fiocruz, que tem como proposta levar a estudantes, profissionais de saúde e público em geral panoramas sobre conceitos e conteúdos fundamentais da área em linguagem acessível, baseados em estudos científicos recentes, como é explicitado na contracapa do livro. A obra é salutar para compreender como a junção de aspectos biomédicos e sociais configuraram uma epidemia que vitimou milhares de crianças e famílias brasileiras, e cujo encerramento pelas autoridades aconteceu sem a efetivação de medidas concretas que evitem surtos no futuro. A obra cumpre a contento as intenções de sua autora que deseja que o livro encoraje seus leitores a se fazerem perguntas difíceis e enfrentar questões inquietantes..

\section{Mônica Mourão Lara Netto 1}

\footnotetext{
1 Instituto de Ciência e Tecnologia em Biomodelos, Fundação Oswaldo Cruz, Rio de Janeiro, Brasil.

monicamouraonetto@gmail.com
}

\section{Informação adicional}

ORCID: Mônica Mourão Lara Netto (0000-00023976-8901).

\section{Referências}

1. Rosenberg C. Explaning epidemics and other studies in the history of medicine. Cambridge: Cambridge University Press; 1992.

2. Löwy I. Zika no Brasil: história recente de uma epidemia. Rio de Janeiro: Editora Fiocruz; 2019. 